\title{
Downward-sloping linear supply function equilibrium in duopoly
}

\author{
Keita Yamane $\mathrm{a}^{*}$
}

${ }^{a}$ Graduate School of Economics, Kobe University, 2-1, Rokkodai, Nada, Kobe 657-8501, Japan

\section{H R O N I C L E}

Article history:

Received: July 5, 2017

Received in revised format: Octo-

ber 10, 2017

Accepted: February 12, 2018

Available online:

February 12, 2018

Keywords:

Duopoly

Linear supply function

Loose cartel

Quadratic cost

\section{A B S T R A C T}

\begin{abstract}
This study examines the properties of the downward-sloping region of the linear supply function equilibrium (cartel case), which has not been considered in the literature. In simple duopoly settings, we find two regions, depending on the cartel type. Specifically, in a tight cartel, fiercer competition yields higher profits to firms, but the equilibrium is unstable. Instead, in the case of a loose cartel, fiercer competition yields lower profits, and the equilibrium is stable. Thus, in our framework, individual firms' profits as a stable equilibrium are maximized not in a pure cartel, but rather in a somewhat weak cartel. This result sheds lights on the situations policymakers should focus on while monitoring cartels.
\end{abstract}

C 2018 by the authors; licensee Growing Science, Canada.

\section{Introduction}

In standard duopoly settings for homogeneous good markets, both prices and firm profits in Cournot competition exceed those in Bertrand competition. Nonetheless, Delbono and Lambertini (2016a) show that Bertrand profits can exceed Cournot ones when firms costs are convex. In another contribution (Delbono \& Lambertini 2016b), the authors obtain similar results after including the linear supply function equilibrium as an intermediate solution between Cournot and Bertrand equilibria.

Since the seminal work by Klemperer and Meyer (1989), the supply function approach has become a useful tool to evaluate competition properties of equilibria between Cournot and Bertrand. In this respect, Delbono and Lambertini (2015) provide a helpful contribution by establishing the parameterization of competition intensity in the context of the "linear supply function" model. Precisely, the authors present the linear supply function $q_{i}=\alpha_{i}+\beta_{i} p$, where $\alpha_{i}$ and $\beta_{i}$ are the strategic variables of each firm $i$. If the firm chooses the intercept $\alpha_{i}$, they show that $\beta$, a symmetric (reciprocal of) slope, leads to the Cournot equilibrium when it approaches 0 , and to the Bertrand equilibrium when it approaches $\infty$. In other words, $\beta \in[0, \infty)$ could be interpreted as a measure for competition intensity.

\footnotetext{
* Corresponding author.

E-mail address: pm08yamane@gmail.com (K. Yamane)

(C) 2018 by the authors; licensee Growing Science, Canada doi: $10.5267 / \mathrm{j} . j p m .2018 .2 .002$
} 
However, Delbono and Lambertini (2015) do not mention the "negative region" of $\beta$, which corresponds to the cartel case. This paper aims to complement their analysis by considering the cartel case in a linear supply function model. Our analysis can be reasonably compared with the relative performance approach, which also covers the cartel case. Nonetheless, we obtain some unusual properties that differ from those in the relative performance approach.

The paper is organized as follows. The next section presents the model and its solution. Section 3 exhibits the results, while Section 4 discusses them. The last section concludes this note.

\section{The model}

We consider a duopoly in which two private firms, 1 and 2, carry on linear supply function competition. The inverse demand function is $p=A-Q$, where $Q=q_{1}+q_{2}$ is the total output and $A$ is large enough. The cost function is identical for both firms and takes a quadratic form, $C_{i}=c q_{i}^{2}$. As for the linear supply function, we consider a simplified form of Delbono and Lambertini's (2015) model. Specifically, the supply function of each firm $i$ is given by

$$
q_{i}=\alpha_{i}+\beta_{i} p, \quad \forall i=1,2
$$

Following Delbono and Lambertini (2015), we assume $\beta_{i}=\beta$. As a consequence, firm $i$ determines the intercept $\alpha_{i}$, and takes the slope as an exogenously given parameter. By substituting Eq. (1) into the inverse demand function and solving the equation with respect to $p$, we obtain

$$
\begin{aligned}
& p=\frac{A-\alpha_{1}-\alpha_{1}}{2 \beta+1}, \\
& q_{i}=\frac{\beta A+(\beta+1) \alpha_{1}-\beta \alpha_{2}}{2 \beta+1} .
\end{aligned}
$$

Using Eq. (2) and Eq. (3), firm $i$ 's profit function, $\pi_{i}=\left(p-c q_{i}\right) q_{i}$, can be written as follows:

$$
\pi_{i}\left(\alpha_{i}\right)=\frac{\left[\beta A+(\beta+1) \alpha_{i}-\beta \alpha_{j}\right]\left[(\beta c-1) A-(\beta c+c+1) \alpha_{i}-(\beta c-1) \alpha_{j}\right]}{(2 \beta+1)^{2}}, \quad j \neq i
$$

From the first-order condition and the symmetry of $\alpha_{i}$, we obtain the (stable or unstable) equilibrium intercept of the supply function,

$$
\alpha^{*}=-\frac{A\left[\left(2 \beta^{2}+2 \beta\right) c-1\right]}{(2 \beta+2) c+2 \beta+3}
$$

The second-order condition is satisfied even under the tight cartel case (see Section 3). Moreover, the stability of the solution is discussed in Section 4.

By substituting Eq. (5) into Eq. (2) and Eq. (4), we obtain, respectively, the following equilibrium price and individual firm's profits:

$$
\begin{aligned}
& p^{*}=\frac{A[(2 \beta+2) c+1]}{(2 \beta+2) c+2 \beta+3}, \\
& \pi_{i}^{*}=\frac{A^{2}(\beta+1)[(\beta+1) c+1]}{[(2 \beta+2) c+2 \beta+3]^{2}} .
\end{aligned}
$$




\section{Results}

First, we derive the cartel solution. In the standard duopoly case, the joint profit function is

$$
\Pi=(A-Q) Q-c Q^{2}+2 c q_{1} q_{2}
$$

which the firm maximizes with respect to $Q$. Assuming $\partial\left(q_{1} q_{2}\right) / \partial Q=0$ for simplicity, we obtain the cartel output as

$$
Q^{C}=\frac{A}{2 c+2}
$$

Solving the equation $Q^{C}=Q^{*}\left(=A-p^{*}\right)$ with respect to $\beta$, we obtain the cartel solution for the slope of the linear supply function:

$$
\beta^{C}=-\frac{2 c+1}{2 c+2}
$$

In the next subsection, we highlight the properties of the solutions obtained with respect to the cartel region of the linear supply function, i.e., $\beta \in\left[\beta^{C}, 0\right)$.

\subsection{Equilibrium price}

By differentiating Eq. (6) with respect to $\beta$, we obtain

$$
\frac{\partial p^{*}}{\partial \beta}=-\frac{2 A}{[(2 \beta+2) c+2 \beta+3]^{2}}<0
$$

implying that the equilibrium price decreases as competition intensifies. Hence, in line with expectations, the cartel price is the highest.

\subsection{Profits in equilibrium}

By differentiating Eq. (7) with respect to $\beta$, we obtain

$$
\frac{\partial \pi_{i}^{*}}{\partial \beta}=-\frac{A^{2}(2 \beta+1)}{[(2 \beta+2) c+2 \beta+3]^{3}} .
$$

The essence of Eq. (12) is summarized by the following proposition:

Proposition 1. $\pi_{i}^{*}$ is maximized when $\beta=-\frac{1}{2}>\beta^{C}$.

Proof. $\partial \pi_{i}^{*} / \partial \beta=0$ yields $\beta^{m}=-\frac{1}{2}$. In this point, $\partial^{2} \pi_{i}^{*}\left(\beta^{m}\right) / \partial \beta^{2}=-\frac{2 A^{2}}{(c+3)^{3}}<0$, and thus $\beta^{m}$ is a local maximum.

Fig. 1 illustrates the main result obtained above.

\subsection{Stability}

In this subsection, we check for the stability of the cartel solution from the viewpoint of the linear supply function equilibrium. 


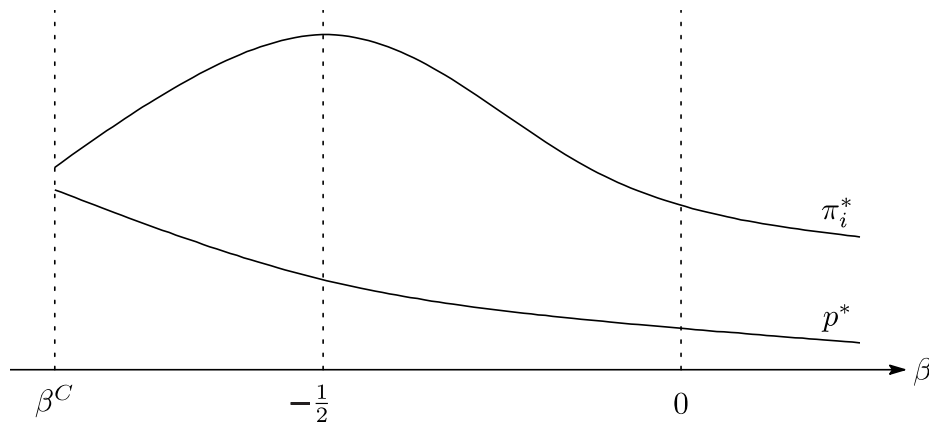

Fig. 1. Competition properties of equilibrium price and profits in the cartel region

The response function of firm $i$ derived from the first-order condition of Eq. (4) is as follows:

$$
\alpha_{i}\left(\alpha_{j}\right)=-\frac{\left(A-\alpha_{j}\right)\left[\left(2 \beta^{2}+2 \beta\right) c-1\right]}{2(\beta+1)[(\beta+1) c+1]}
$$

or

$$
\alpha_{i}^{\prime}\left(\alpha_{j}\right)=\frac{\left(2 \beta^{2}+2 \beta\right) c-1}{2(\beta+1)[(\beta+1) c+1]} .
$$

The denominator of Eq. (14) is positive since $\beta+1>0$ and $(\beta+1) c+1>0$ for all $\beta \in\left[\beta^{C}, 0\right)$. Thus, the sign of the equation is determined by the numerator. Solving the equation $\left(2 \beta^{2}+2 \beta\right) c-$ $1=0$ for $\beta$, we find the negative solution $\beta=-\left(\sqrt{c^{2}+2 c}+c\right) /(2 c)$, which is lower than $\beta^{C}$. Hence, Eq. (14) is always negative, implying that $\alpha_{i}$ and $\alpha_{i}^{\prime}$ are strategic substitutes for all $\beta \in\left[\beta^{C}, 0\right)$.

We now confirm the stability of $\alpha^{*}$. Since $\alpha_{i}^{\prime}\left(\alpha_{j}\right)$ is negative, if the term $X$ (explained below) is positive, $\alpha^{*}$ is stable, while it is unstable if $X$ is negative.

$$
X=-\frac{1}{\alpha_{i}^{\prime}\left(\alpha_{j}\right)}-\left(-\alpha_{j}^{\prime}\left(\alpha_{i}\right)\right)=\frac{(2 \beta+1)[(2 \beta+2) c+1][(2 \beta+2) c+2 \beta+3]}{2(\beta+1)[(\beta+1) c+1]\left[-\left(2 \beta^{2}+2 \beta\right) c+1\right]}
$$

Note that for $\beta \in\left[\beta^{C}, 0\right)$, all the terms in Eq. (15) except for $2 \beta+1$ are positive. Hence, $\alpha^{*}$ is unstable if $\beta \in\left[\beta^{C},-\frac{1}{2}\right)$ and stable if $\beta \in\left[-\frac{1}{2}, 0\right)$.

We call the interval $\left[\beta^{C},-\frac{1}{2}\right)$ as 'tight cartel', and $\left[-\frac{1}{2}, 0\right)$ as 'loose cartel'.

Proposition 2. The cartel solution as a linear supply function equilibrium is stable if $\beta$ is in the loose cartel region.

\section{Discussion}

\subsection{The logic for the stability}

We explain the logic behind Proposition 2 from the viewpoint of Walrasian stability. As for the industrial supply function, from Eq. (1) we derive 


$$
Q=\sum_{i=1}^{2} \alpha_{i}+2 \beta p
$$

Hence, the absolute value of the slope is $-\frac{1}{2 \beta}$, which exceeds or equals 1 (i.e., the absolute value of the slope of the demand function) if $\beta \in\left[-\frac{1}{2}, 0\right)$. That is, the cartel solution is stable if $\beta \in\left[-\frac{1}{2}, 0\right)$ and unstable if $\beta<-\frac{1}{2}$.

\subsection{Social welfare}

Another interesting aspect relates to social welfare $W$, that is, the sum of consumer surplus and firms' profits. Since we obtain

$$
\begin{aligned}
& W=\frac{2 A^{2}(\beta+1)[(\beta+1) c+\beta+2]}{[(2 \beta+2) c+2 \beta+3]^{2}} \text { and } \\
& \frac{d W}{d \beta}=\frac{2 A^{2}}{[(2 \beta+2) c+2 \beta+3]^{3}}>0 \quad \forall \beta \in\left[\beta^{C}, 0\right),
\end{aligned}
$$

social welfare turns out to be lower in the cartel region than in other supply function regions. This result probably originates from the fact that the decrease in the consumer surplus offsets the increase in firms' profits under a cartel. ${ }^{1}$

\subsection{Comparison with the relative performance approach}

It is somewhat important to compare the results of the linear supply function approach with another approach. For this reason, we consider the relative performance approach as a comparison term. ${ }^{2}$

The relative profit of firm $i$ is represented as follows:

$$
v_{i}=\pi_{i}-t \pi_{j}, \quad j \neq i
$$

The parameter $t \in[-1,1]$ indicates competition intensity. Specifically, $t=1$ corresponds to Bertrand competition, $t=0$ to Cournot competition, and $t=-1$ to the cartel. As a consequence, the interval $t \in[-1,0)$ indicates the cartel region and thus corresponds to $\beta \in\left[\beta^{C}, 0\right)$.

The first-order condition on Eq. (19) yields the following equilibrium values for price and profits:

$$
p^{e}=\frac{A(2 c+1-t)}{2 c+3-t}, \quad \pi_{i}^{e}=\frac{A^{2}(c+1-t)}{(2 c+3-t)^{2}}
$$

By differentiating these values with respect to $t$, we obtain $d p^{e} / d t<0$ and $d \pi_{i}^{e} / d t \leq 0$ for all $t \in$ $[-1,0){ }^{3}$ Thus, we can conclude that the competition property in the cartel regions within the linear

\footnotetext{
${ }^{1}$ In most of the homogenous good cases, the direction of the consumer surplus (namely, prices) change corresponds to that of social welfare. See, for instance, Motta (2004, section 7.2).

${ }^{2}$ For an example of the relative performance approach, see Miller and Pazgal (2001). Another approach is, for instance, the conjectural variation approach. However, we do not adopt it because of the criticisms against the method (e.g., Makowski 1987; Martin 2002; Tirole 1988) mainly for its contradiction on dynamical procedure.

${ }^{3}$ The equation is satisfied when $t=-1$.
} 
supply function approach differs from that of the relative performance approach. The relative performance model seems to be appropriate to depict the standard manufacturing industry ${ }^{4}$ while the supply function equilibria model is suitable for the electricity market (see Green and Newbery 1992). Thus, policymakers should flexibly monitor and analyze the performance of cartels according to their target markets.

\section{Conclusion}

In this paper, we have considered a linear supply function approach and investigated competition properties in a cartel region, which is not referred to in the related literature. We have found somewhat unusual properties for individual firms' profits as, contrary to the expectations, the related equilibrium turns out to be more stable when the cartel is loose. Thus, policymakers may have to monitor loose cartels more carefully than tight ones. Future research should extend the duopoly setting to a more general oligopoly model, although we expect similar results as long as we consider symmetric equilibria. In addition, it would be interesting to analyze the product differentiation case. Lastly, as with Delbono and Lambertini (2016b), we could examine the performance ranking by adding the cartel case to the Cournot, Bertand, and linear supply function equilibria.

\section{Acknowledgements}

The author is grateful to Takashi Yanagawa (Kobe University) and the anonymous referees for their helpful comments and suggestions.

\section{References}

Delbono, F., \& Lambertini, L. (2015). On the properties of linear supply functions in oligopoly, Economics Letters, 136, 22-24.

Delbono, F., \& Lambertini, L. (2016a). Bertrand versus Cournot with convex variable costs. Economic Theory Bulletin, 4(1), 73-83.

Delbono, F., \& Lambertini, L. (2016b). Ranking Bertrand, Cournot and supply function equilibria in oligopoly, Energy Economics, 60, 73-78.

Green, R. J., \& Newbery, D. M. (1992). Competition in the British electricity spot market. Journal of Political Economy, 100(5), 929-953.

Klemperer, P. D., \& Meyer, M. A. (1989). Supply function equilibria in oligopoly under uncertainty, Econometrica, 57(6), 1243-1277.

Makowski, L. (1987). Are 'rational conjectures' rational? Journal of Industrial Economics, 36(1), 35-47.

Matsumura, T. (2012). Sotai rijun approchi ga hiraku atarashi sangyo soshiki, in Ogaki, M., Ogawa, K., et al. (Eds): Gendai Keizaigaku no Choryu 2012 (in Japanese), Toyo Keizai inc., 65-92.

Martin, S. (2002). Advanced Industrial Economics, 2nd ed., Blackwell: Oxford.

Miller, N. H., \& Pazgal, A. I. (2001). The equivalence of price and quantity competition with delegation. RAND Journal of Economics, 32(2), 284-301.

Motta, M. (2004). Competition Policy: Theory and Practice, Cambridge University Press.

Tirole, J. (1988). The Theory of Industrial Organization, MIT Press: Cambridge.

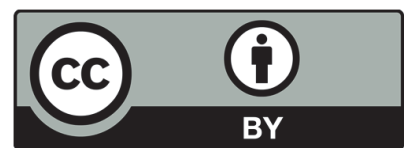

(C) 2018 by the authors; licensee Growing Science, Canada. This is an open access article distributed under the terms and conditions of the Creative Commons Attribution (CC-BY) license (http://creativecommons.org/licenses/by/4.0/).

\footnotetext{
${ }^{4}$ Matsumura (2012) claims that quite a few firms in many industries have rivalry to other firms and thus they maximize
} relative profits rather than absolute profits. 